\title{
Abortamento e morte embrionária em receptoras bovinas por Histophilus somni (Haemophilus somnus)
}

\author{
Abortion and embryonic death in bovine recipients due to Histophilus somni (Haemophilus somnus) \\ Eliana Scarcelli ${ }^{1}$, Margareth Élide Genovez ${ }^{1}$, Maristela Vasconcellos Cardoso ${ }^{1}$, \\ Fabíola Ribeiro Campos ${ }^{1}$, Simone Miyashiro ${ }^{1}$, Rosa Maria Piatti ${ }^{1}$, Solange Rosa Teixeira ${ }^{1}$, \\ Eliana de Stefano ${ }^{2}$, Líria Hiromi Okuda² \& Edwiges Maristela Pituco²
}

\begin{abstract}
RESUMO
Histophilus somni (Haemophilus somnus) é um importante patógeno que pode desencadear quatro diferentes tipos de manifestações: doença respiratória, meningoencefalopatia trombótica (TEM), artrite e distúrbios reprodutivos. A via de infecção geralmente é a respiratória, porém nos distúrbios reprodutivos, pode ser transmitido através de muco prepucial, sêmen e secreções vaginais contaminadas causando metrite, infertilidade, morte embrionária precoce, abortamento ao redor dos 6 a 9 meses de gestação por morte fetal ou placentite, vulvovaginite granular e orquiepidimite crônica. O presente trabalho tem por objetivo relatar o isolamento e detecção pela Reação da Polimerase em Cadeia (PCR) de Histophilus somni de um feto bovino abortado e de um aspirado uterino de duas receptoras de embrião da raça Red Angus, oriundas de gado de corte da região de Campo Grande-MS. Trata-se do primeiro caso no Brasil de isolamento de H. somni de aborto bovino, demonstrando a importância do diagnóstico diferencial mais abrangente. Além disto, ressalta-se também o risco sanitário de transmissão de H. somni por transferência de embriões.
\end{abstract}

Descritores: Histophilus somni, Haemophilus somnus, abortamento, morte embrionária, bovino.

\begin{abstract}
Histophilus somni (Haemophilus somnus) is an important pathogen that may produce four different kinds of diseases: respiratory disease, thromboembotic meningoencephalopathy (TEM), arthritis and reproductive disorders. Although infection generally occurs by respiratory route, in reproductive disorders it may also be transmitted by means of prepucial mucus, semen and contaminated vaginal secretions. The objective of the present trial was to report an abortion and an embryonic death caused by Histophilus somni, affecting two recipients of Red Angus, from a beef cattle herd in Campo Grande-MS, Brazil. This was the first case of $H$. somni isolation from bovine aborted foetus in Brazil, which shows the importance of a more extensive differential diagnosis procedures. The role of $H$. somni in embryo transfer still requires further studies.
\end{abstract}

Key words: Histophilus somni, Haemophilus somnus, abortion, embryonic death, bovine. 


\section{INTRODUÇÃO}

Histophilus somni (Haemophilus somnus) é um importante patógeno que pode desencadear quatro diferentes tipos de manifestações: doença respiratória, meningoencefalopatia trombótica (TEM), artrite e distúrbios reprodutivos; além de otite, conjuntivite, cegueira, mastite e septicemia $[1,6,11,13]$. Essas manifestações clínicas podem ocorrer no mesmo animal, sendo a nervosa (TEM) freqüentemente fatal. Na fêmea se observam descargas vulvares, metrite, vulvovaginite granular, infertilidade por morte embrionária precoce, abortamento por morte fetal e placentite ao redor de 6-9 meses de gestação, podendo ocorrer retenção de placenta; enquanto no macho ocorre balanopostite e sêmen muco-purulento. Por outro lado, pode ser isolado do trato urogenital de até $90 \%$ de machos e $28 \%$ de fêmeas sadias, comportando-se como microrganismo comensal [3,13,27]. A via de infecção geralmente é a respiratória através de aerossóis, porém nos distúrbios reprodutivos pode ser transmitido através de urina, sêmen, muco prepucial e secreção cérvico- vaginal contaminada [11,13].

Este trabalho tem por objetivo relatar o isolamento e detecção por PCR de Histophilus somni de um aspirado uterino contendo embrião (50 dias) e de um feto de seis meses de gestação, provenientes de duas receptoras de embrião da raça Red Angus, de um rebanho da região de Campo Grande-MS.

\section{MATERIAIS E MÉTODOS}

Um rebanho de corte, de manejo extensivo, da raça Red Angus, proveniente da região de Campo Grande-MS, vacinado contra IBR, BVD e leptospirose, que utiliza TE, apresentou perda embrionária (50 dias) e abortamento de feto com 6 meses de gestação em duas receptoras, num mesmo período. Para investigação dos possíveis agentes etiológicos, os materiais fetais e aspirado uterino foram submetidos aos processamentos bacteriológico, virológico, parasitário e molecular (PCR).

Bacteriológico: Foram pesquisadas bactérias aeróbias e microaerófilas considerando-se como possíveis causas de abortamento, os microrganismos isolados em cultura pura ou preponderantes [7,21]. Fragmentos de cada órgão (pulmão, fígado, rim e baço) do feto foram processadas em aparelho homogeneizador (Stomacher 80) por dois minutos. Cem $\mu$ d deste material, do conteúdo abomasal fetal e do aspirado uterino contendo em- brião foram individualmente investigados, através de diversos protocolos descritos na literatura (isolamento e PCR), para os seguintes microorganismos: Brucella spp e Leptospira spp. [7,25]; Campylobacter spp. [7,14]; Histophilus somni (Haemophilus somnus) [2,28]; Mycoplasma spp. e Ureaplasma diversum $[4,18]$. Para cultivo de aeróbios (Staphylococcus aureus, Streptococcus spp), enterobactérias (Escherichia coli, , Salmonella spp.) e Arcobacter spp. [7,26]. Os cultivos foram identificados de acordo com o agente suspeito, segundo Bergey's Manual of Systematic Bacteriology [12]. Para Histophilus somni, também foi utilizado o sistema de identificação APIZYM (Bio-Merieux) empregando-se estirpe padrão ATCC 43625 como controle [8, 27].

Virológico: uma alíquota do aspirado uterino e uma suspensão a $20 \%$ (p/v) de órgãos (pulmão, fígado, rim, coração, cérebro e baço) do feto foi processada para isolamento e detecção por PCR dos vírus Herpes Vírus bovino-1 (BHV-1), Herpes Vírus Bovino-5 (BHV5) e Diarréia Viral Bovina (BVDV) [21, 23, 24].

Parasitológico: Uma suspensão a 20\% (p/v) do cérebro fetal foi processada para verificar a presença de taquizoítos e cistos de $N$. caninum e Toxoplasma gondii $[19,20]$.

A detecção dos produtos amplificados pelas PCRs foi realizada por eletroforese em gel de agarose a $2 \%$, corado com brometo de etídeo, visualizado em transiluminador U.V. e fotografado em câmera digital (Kodak digital Science DC-40 Camera).

\section{RESULTADOS}

O diagnóstico diferencial apresentou resultados negativos para Brucella spp., Leptospira spp., Campylobacter spp., Mycoplasma spp., Ureaplasma diversum, Arcobacter spp., IBR, BVD, Toxoplasma gondii e Neospora caninum tanto no cultivo como na PCR em todas os materiais.

A partir das amostras do feto (6 meses) foi possível o isolamento e identificação em cultura pura de Histophilus somni (Figuras 1 e 2), mas não do aspirado uterino; entretanto pela PCR foram revelados fragmentos amplificados de $400 \mathrm{pb}$, como mostra a Figura 3, nas amostras de conteúdo abomasal e do pool de órgãos deste feto e ainda do aspirado uterino contendo embrião. As colônias isoladas do feto foram confirmadas como sendo Histophilus somni também pela PCR. 


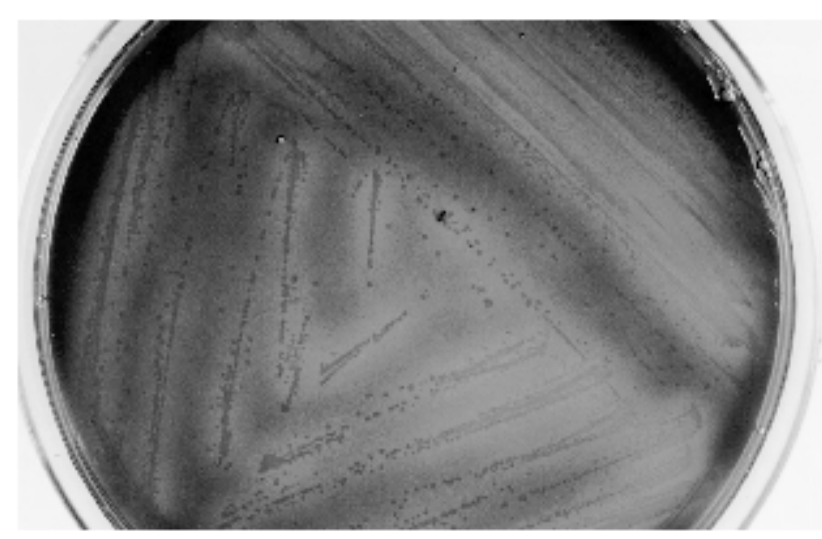

Figura 1. Crescimento de Histophilus somni em BHI ágar mostrando zona de clareamento em torno das colônias.

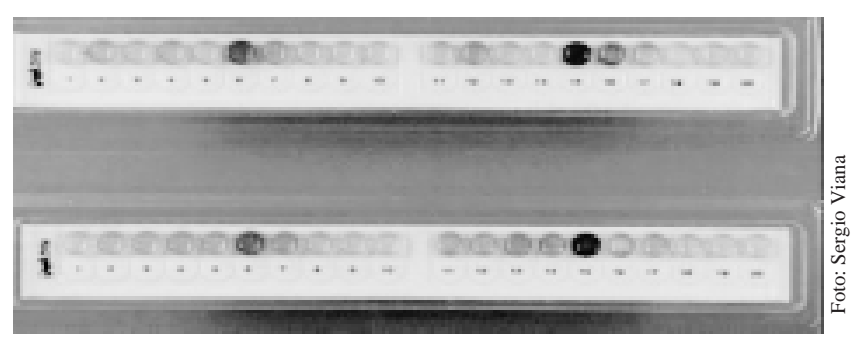

Figura 2. Sistema de identificação API-Zym - Bio Merieux: 1. Estirpe padrão ATCC 43625; 2. Estirpe de Histophilus somni isolada do feto abortado de 6 meses.

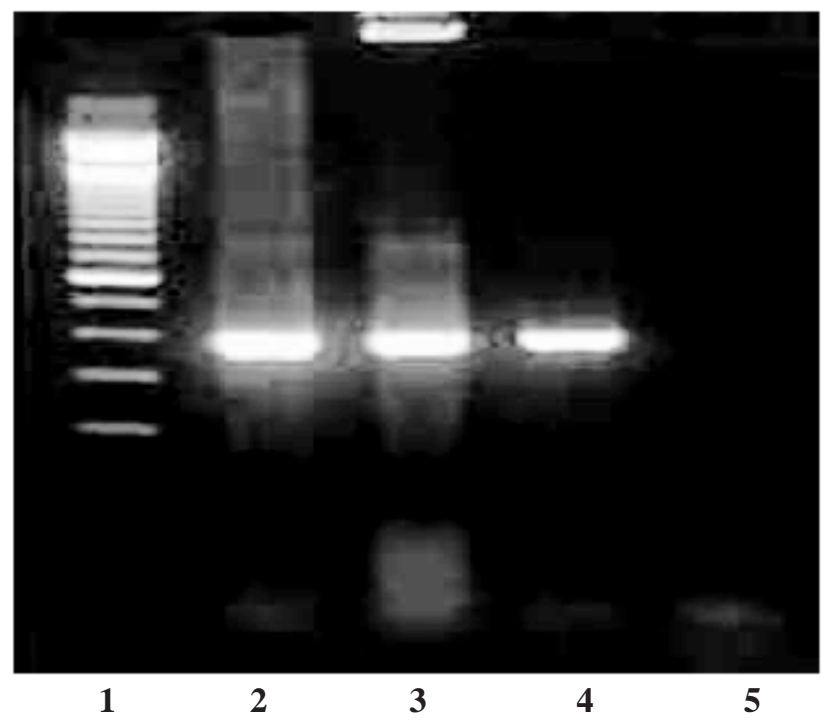

Figura 3. Resultados obtidos através da amplificação por PCR para detecção de Histophilus somni: 1) Marcador DNA Ladder (100 bp); 2) Conteúdo abomasal do feto abortado aos 6 meses de gestação; 3) Aspirado uterino contendo embrião de 50 dias de gestação; 4) Controle positivo Histophilus somni (Haemophilus somnus - ATCC 43625); 5) Controle negativo.

\section{DISCUSSÃO}

As infecções por microrganismos (vírus, bactérias, protozoários) podem resultar em mortalidade embrionária direta, ao afetarem o embrião ou contaminarem o ambiente intra-uterino. Indiretamente, o embrião pode sucumbir por efeitos sistêmicos devido a septicemias, viremias ou toxemias [10].

Em vários países, e principalmente na América do Norte a TEM, tem sido mais descrita em gado de corte do que leiteiro e geralmente em animais criados a pasto; com envolvimento de fator sazonal, ocorrendo mais no outono e inverno. Nesses países há evidências de que a taxa de infecção em bovinos seja relativamente alta, com morbidade em grupos afetados de $2-5 \%$, eventualmente chegando a $30 \%$. Em animais clinicamente doentes e não tratados a mortalidade atinge $100 \%$ [11].

Atualmente, com o avanço do uso da transferência de embriões (TE) a histofilose bovina na forma reprodutiva tem merecido maiores preocupações quanto ao potencial de risco de transmissão desse agente. $\mathrm{O}$ risco sanitário associado com TE depende não somente dos animais doadores (oócito e sêmen) mas do meio ambiente ao qual os gametas são expostos (meios de cultura, condições de estocagem e transferência), como também às receptoras. Estas, geralmente pouco focadas nos aspectos sanitários [9] e de seleção, levando-se mais em conta condição corporal e custo da aquisição, principalmente quando se trata de grandes lotes de TE. O uso da vacinação contra IBR, BVD e leptospirose das doadoras e receptoras, como única medida sanitária sem que outras ações sejam tomadas, tem se mostrado insuficiente. Como se observa, outros agentes não contemplados nas vacinas comerciais podem conduzir a prejuízos, colocando em risco a eficiência da TE no rebanho. Os procedimentos preventivos aplicados ao sêmen, às doadoras e receptores propostos pela International Embryos Transfer Society (IETS) e Office International Des Epizooties (OIE) visam minimizar os riscos de transmissão ao embrião [22], entretanto a eficiência destes métodos está diretamente relacionada à observância do cumprimento de forma correta de todas as etapas.

Uma proposta para o monitoramento das condições sanitárias da TE, que está sendo realizada no rebanho, seria a análise laboratorial de pelo menos duas amostras representantes das duas etapas mais importantes: $10 \mathrm{~mL}$ do primeiro lavado uterino para a 
colheita do embrião da doadora, que traria evidencias sanitárias da doadora e $10 \mathrm{~mL}$ do conteúdo da placa de procura de embriões, contendo embriões degenerados e óvulos não fecundados, que enfocaria a eficiência dos procedimentos referentes ao lote de embriões a ser transferido.

No presente relato, o abortamento ocorrido em duas receptoras da mesma propriedade mostra ter havido falha, quer seja na utilização de doadores (oócito e sêmen) ou nas receptoras infectados, quer seja na ineficiência ou escape nos procedimentos de lavagem praticados; os quais, não puderam ser esclarecidos, pois amostras das doadoras e das receptoras não foram enviadas para a análise laboratorial, depois de estabelecido o diagnóstico.

A presença e a capacidade de transmissão de Histophilus somni pelo sêmen contaminado já foram descritas [10]. O estudo da influência direta por tres horas do cultivo do H. somni sobre o sêmen in natura, demonstrou perda progressiva da motilidade com grande número de espermatozóides mortos e adesão do H. somni adjacente à cabeça, à peça intermediária $\mathrm{e}$ ao flagelo[5].

A inoculação intra-uterina de $H$. somni em novilhas produziu mais embriões degenerados, com menor período de sobrevivência nos co-cultivos, maior número de cistos foliculares e menor proporção embrião/corpo lúteo após a super ovulação e portanto, menor coleta de embriões das novilhas inoculadas quando comparadas às fêmeas do grupo controle, demonstrando que H. somni afeta a atividade ovariana [15-17]. Outro estudo já comprovou o elevado risco de contaminação do oócito pelo enorme potencial de ligação à zona pelúcida [9]. O efeito in vitro do $H$. somni sobre à zona pelúcida intacta, também já foi estudado [29], e os resultados demostraram que de 42 embriões expostos, 10 foram bacteriologicamente positivos, enquanto nenhum dos tratados com antibióticos. No entanto, todos os embriões iniciaram processo de degeneração após 18 horas de exposição, o que sugere que $H$. somni apresenta papel importante na infertilidade. Este agente adere à zona pelúcida, mas é sensível aos antibióticos usados nos meios de colheita, lavagem e cultivo, incubados por 2 horas [29]. Deve-se ressaltar que o diagnóstico da histofilose reprodutiva pode ser prejudicado pela baixa sensibilidade dos métodos bacteriológicos, o que explicaria a restrita taxa de isolamento relatada na literatura, sendo aconselhável nestes casos, a associação de outras técnicas de diagnóstico mais sensíveis e específicas como a PCR [28].

\section{CONCLUSÃO}

A importância deste trabalho reveste-se no alerta do diagnóstico dos primeiros casos de abortamento com isolamento de Histophilus somni no Brasil em fêmeas bovinas receptoras de embrião.

\section{REFERÊNCIAS}

1 Angen O., Ahrens P., Kuhnert P., Christensen H. \& Mutters R. 2003. Proposal of Histophilus somni gen. Nov., sp. Nov. for three species incertae sedis "Haemophilus somnus", "Haemophilus agni" e "Histophilus ovis". International Journal of Systematic Evolutionary Microbiology. 53: 1449-1456.

2 Angen O., Ahrens P. \& Tegtmeier C. 1998. Development of a PCR test for identification of Haemophilus somnus in pure and mixed cultures. Veterinary Microbiology. 63: 39-48.

3 Campero C. M., Moreira A. R., Daguerre S., Bartolome J. \& Odriozola E. 1993. Bovine abortion associated with Haemophilus somnus. Veterinaria Argentina. 10: 404-409.

4 Cardoso M. V., Scarcelli E., Genovez M. E., Grasso L. M. P., Teixeira S. R. \& Timenetsky J. 1999. Ureaplasma diversum e Mycoplasma spp em disfunções reprodutivas inespecíficas de vacas e novilhas de rebanhos do Estado de São Paulo, Brasil. Revista Brasileira de Reprodução Animal. 23: 408-409.

5 Chelmonska A. The influence of Haemophilus somnus on bull sperms examined in vitro. 1990. Polskie Archiwum Weterynaryjne. 30: 141-154.

6 Eagleasome M. D., Garcia M. M. \& Stewart R. B. 1992. Microbial agents associated with bovine genital tract infection and semen: Part II: Haemoplilus somnus, Mycoplasma spp and Ureaplasma spp, Chlamidia; Pathogens and semen contaminants; treatment of bull semen with antimicrobial agents. Veterinary Bulletin. 62: 887-910. 
7 Genovez M. E., Scarcelli E., Rojas S., Giorgi W. \& Kaneto C. N. 1993. Isolamentos bacterianos de fetos abortados bovinos examinados no Instituto Biológico de São Paulo, no período de 1985-1992. Brazilian Journal of Veterinary Research and Animal Science. 30: 107-112.

8 Groom S. C., Hazlett M. J. \& Little P. B. 1986. An evatuation of the API ZYM system as a means of identifying Haemophilus somnus and related taxa. Canadian Journal of Veterinary Research. 50: 238-244.

9 Guerin B., Nibart M., Marquant-Le Guienne B. \& Humblot P. 1997. Sanitary risks related to embryo transfer in domestic species. Theriogenology. 47: 33-42.

10 Hare W. C. D. 1985. Enfermidades transmissibles por el semen y las tecnicas de transferencia de embriones. Office International Des Epizooties, Serie Tecnica OIE, (4). 83 p.

11 Harris F. W. H \& Janzen E. D. 1989. The Hemophilus somnus disease complex (Hemophilosis): A review. Canadian Veterinary Journal. 30: 816-822.

12 Holt J. G., Krieg N. R., Sneath P. H. A., Staley J. T. \& Willians S. T. 1994. Bergey's manual of determinative bacteriology. 9th edn. Baltimore: Williams \& Wilkins, 789p.

13 Humphrey J. D., Little P. B., Stephens L. R., Barnum D. A., Doig P. A. \& Thorsen J. 1982. Prevalence and distribuition of Haemophilus somnus in the male bovine reproductive tract. American Journal of Veterinary Research. 43: 791-795.

14 Hum S., Quinn K., Brunner J. \& On S. L. J. 1997. Evaluation of a PCR assay for identification and differentiation of Campylobacter fetus subspecies. Australian Veterinary Journal. 75: 827-831.

15 Kaneene J. B., Coe P. H., Gibson, C. D., Yamini B., Marinez R. O. \& Morrow D. A. 1986. The role of Haemophilus somnus in bovine early embrionic death. The effect of the organism on embryos by day 8 postbreeding. Theriogenology. 26: 189-199.

16 Kaneene J. B., Gibson C. D., Coe P. H. \& Morrow D. A. 1986. The role of Haemophilus somnus in bovine early embrionic death. persistence of the organism in the uterus following intrauterine exposure. Theriogenology. 26: 795-801.

17 Kaneene J. B., Coe P. H., Gibson C. D., Yamini B., Morrow D. A. \& Marinez R. O. 1987. The role of Haemophilus somnus in bovine early embrionic death. The effect of the organism on embryos by day 21 postbreeding. Theriogenology. 27: 737-749.

18 Kuppeveld F. J. M., Logt J. T. M., Angulo A. F., Zoest M. J., Quint W. G. V., Niesters H. G. M., Galama J. M. D. \& Melchers W. J. G. 1992. Genus- and species-specific identification of Mycoplasmas by 16 rRNA amplification. Applied and Environmental Microbiology. 58: 2606-2615.

19 Lin M.H., Chen T.C., Kuo T. T., Tseng C.C. \& Tseng C. P. 2000. Real-Time PCR for quantitative detection of Toxoplasma gondii. Journal of Clinical Microbiology. 38: 4121-4125.

20 Müller N., Zimmermann V., Hentrich B. \& Gottstein B. 1996. Diagnosis of Neospora caninum and Toxoplasma gondii infection by PCR and DNA hybridization Immunoassay. Journal of Clinical Microbiology. 34: 2850-2852.

21 Office International Des Epizooties. 2000. Manual of standars for diagnostic tests and vaccines. World Organisation for Animal Health. 4th edn. Disponível em: http://www.oie.int/eng/normes/mmanual/A_00065.htm. Acesso em: 5 de março 2003.

22 Office International Des Epizooties. 2002. International Animal Health Code. Paris: OIE.

23 Pituco E. M. 1995. Análise da Diversidade Antigênica do Vírus da Diarréia Viral Bovina em Isolados de Campo Obtidos no Período de 1959 a 1994 com o uso de anticorpos monoclonais. Tese (Doutorado em Virologia) - Instituto de Virologia, Escola Superior de Medicina Veterinária Hannover-Alemanha.

24 Pituco E M., Stefano, E., Okuda L.H., Paraventi R. \& Romano C.M. 1999. Detecção do Herpesvírus Bovino1 (HVB-1) e do vírus da Diarréia Viral Bovina (BVDV) pela Imunofluorescência Direta (IFD) em fetos bovinos abortados. Arquivos do Instituto Biológico. 66 (supl): 44.

25 Richtzenhain L. J., Cortez A., Heineman M. B., Soares R. M., Sakamoto S. M., Vasconcellos S. A., Higa Z. M. M., Scarcelli E. \& Genovez M. E. 2002. A multiplex PCR for the detection of Brucella spp. and Leptospira spp. DNA from aborted bovine fetuses. Veterinary Microbiology. 87: 139-147.

26 Scarcelli E., Genovez M. E., Bersano J. G. \& Cardoso M. V. 1998. Isolamentos de Arcobacter cryaerophilus de fetos suínos e bovinos abortados no Estado de São Paulo. Arquivos do Instituto Biológico. 65: 131-133. 
27 Scarcelli E., Genovez M. E., Cardoso, M. V., Almeida Prado W. D. N., Faccioli M. R. \& Teixeira S. R. 2000. Presence of Haemophilus somnus in breeding bulls from Minas gerais, São Paulo and Rio Grande do Sul, Brazil. In: Proceedings do $23^{\circ}$ Congresso Mundial de Buiatria (Punta del Este, Uruguay). CD-ROM, 1 computer disc $5^{1 / 4}$ in, 7941-7945.

28 Tegtmeier C., Angen O. \& Ahrens P. 2000. Comparison of bacterial cultivation, PCR, in situ hybridization and immunohistochemistry as tools for diagnosis of Haemophilus somnus pneumonia in cattle. Veterinary Microbiology.76: 385-394.

29 Thompson M. S., Stringfellow D. \& Lauerman L. H.1988. Adherence of Haemophilus somnus to a bovine embryos after "in vitro" exposure. American Journal of Veterinary Research. 49: 63-66. 